\title{
Home, School and Gender Differences in Early Reading Fluency among Standard Three Pupils in Primary Schools in Kiuu Sublocation, Kiambu County, Kenya
}

\author{
Tabitha Wang'eri", Doyne Mugambi \\ Department of Educational Psychology, P. O. Box 43844-00100, Nairobi-Kenya \\ *Corresponding author: tabitha.wangeri@gmail.com
}

Received September 15, 2014; Revised September 30, 2014; Accepted October 21, 2014

\begin{abstract}
The intention of the study was to establish the relationship between home and school factors and reading fluency in Kiswahili and English languages among standard three pupils in Kiuu sub location, Kiambu County, Kenya. To achieve this, the study investigated family factors such as family size, number of children attending school, languages spoken at home, parental support such as helping with homework and the frequency of reading story books for children. The study also sought to establish school factors that support reading fluency such as languages of instruction teachers used as well as the number of Kiswahili and English text books children possessed. Bronfennbrener (1979) ecological systems theory was used to ground the study. The study sample consisted of four purposefully selected primary schools two of which were public and the other two privately owned. Data regarding the school and home factors were collected through a paper based questionnaire while the data relating to pupils' Kiswahili and English reading fluency was collected through one-minute reading passages one in Kiswahili and the other in English. The results revealed that majority of the children lived with both parents and had between 1 and 3 siblings in school and the languages spoken at home, school and among the peers were mother tongue, Kiswahili and English. For majority of the children homework was overseen by the mother while many of them could not recall the last time a parent read to them a story book. With regard to accessing books for reading, the findings revealed that children in private schools had more access to English and Kiswahili books than their counterparts in public schools. With regard to reading fluency, the study established that the maximum number of English words read per minute were 171 while the least were 0 with a mode of 69 . The maximum number of Kiswahili words read was 118 with a minimum of 0 and a mode of 61 . Children in Private schools displayed better fluent reading than their counterparts in public schools and girls were more fluent readers than boys. The study recommended that the literary environments be improved both at home and in the schools and that the language policy be further interrogated given that the language children are exposed to at home is different from the language of instruction at school and also different from the language used among peers. Another recommendation of this study was that curriculum developers engage in material development both in Kiswahili and the various local languages in tandem with policy requirements. The study further recommended that methods of improving reading acquisition and fluency be sought.
\end{abstract}

Keywords: reading fluency, public primary school, private primary school, gender differences

Cite This Article: Tabitha Wang'eri, and Doyne Mugambi, "Home, School and Gender Differences in Early Reading Fluency among Standard Three Pupils in Primary Schools in Kiuu Sublocation, Kiambu County, Kenya." American Journal of Educational Research, vol. 2, no. 10 (2014): 932-941. doi: 10.12691/education-2-10-13.

\section{Introduction}

Reading fluency defined as the ability to read text accurately is a crucial skill for all school going children as it sets the foundation of intellectual development due to its intricate relationship with comprehension [1]. Reading fluency has also been related to academic success and as such it must be acquired during early childhood education [2]. Its acquisition is determined by several factors identified as acquisition of oral language and the child's early linguistic experiences [3]. The child's early linguistic experiences are related to family environments which if enriched nurture language acquisition. On the other hand if the early linguistic environments are impoverished language development is stunted. Important variables determining the quality of language development in children have been identified as the amount of words and literacy materials like books, letters, numbers and older people who use language and engage children in the use of language. Important environments that nurture intellectual development and consequently the foundational skills like reading fluency have been recognized as the home and the school. Homes that provide for children's reading fluency needs provide 
reading materials and they also provide support to the children's unfolding literacy by reading for them, helping them with literacy tasks as well as providing conducive environments for the children's development of reading skills at home. In line with this, various studies seem to concur that parents must be overtly involved in the child's reading while other studies report a positive relationship between parental involvement and the child's reading achievement and vocabulary skills [4,5]. In addition, parental involvement in children's early learning has been associated with enhanced intrinsic motivation and less anxiety about school [6,7]. Thus individual differences in children's reading fluency may be explained by the differences in the home support children receive.

Literature has supported the benefits of exposing children to literacy materials such as story books at home. A long standing assertion among researchers is that children who are exposed to formal and informal literacy activities for example when a parent reads a bed time story to a child the child gets the message in the story are likely to be better readers than their counterparts without such benefit [8]. A longitudinal study found that children's exposure to books was related to development of vocabulary and listening comprehension skills and these skills were related to children's reading in grade three [9]. Parental involvement in teaching children reading and writing skills has also been related to acquisition of early literacy skills as well as reading fluency in grade three.

Schools constitute formal environments that nurture development of reading fluency. The foundational skills for development of reading fluency have been identified as the ability to decode and comprehend text [10]. This study recognizes that schools differ in the support thy accord children's reading fluency just like the homes, a situation that may cause variance in reading fluency among children. Important school factors have been identified as the availability of resources that support early reading fluency. Class size and pupil-teacher ratio as well as the availability of reading materials are important factors in supporting early reading fluency at the school level. According to research exposure to books in situations beyond shared parent-child reading seem to have a role in the development of fluent reading. Indeed adequate mastery of at least a mother tongue before the child enters school is has been deemed an important predictor of reading acquisition [11]. Despite the awareness of the predictors of early reading acquisition in sub-Saharan Africa low literacy levels continue to be observed [12].

\subsection{Theoretical Framework}

The study was grounded by human ecology theory which envisages the individual's development as being shaped by the individual child's biology and the nurturing influences of the various environments that interact with the child directly or the child's family [13]. Environments that are important early in life when the child is developing oral language and literacy are the family, school, neighborhood, peers and they constitute the micro system. Individual families interact with other systems like the school to determine the acquisition of both oral language and literacy. The systems that directly interact with families are called the meso-systems and they are related to the national policies regarding language of instruction and the social economic factors that may determine whether or not parents are able to provide conditions that support reading fluency or not. The macrosystem in this respect will consist of the world trends in be nurturing at home determines how the child interacts with others outside the home. The theory recognizes that the families interact with wider social institutions and hence the existence of the Exosystem which involves the links between social settings-a parent who gets promoted may spend more time at work. Macrosystem describes cultural influences- identity, heritage and values which for the purposes of this paper may refer to the World trends that guide education in every country. The Chronosystem refers to the social-historical circumstances that determine the effects of various events in the dimension of time which in this paper may be the experiences the children are exposed to and which have a bearing on their reading fluency. Examples of these are the exposure of several languages and the environments of early reading which for pupils in public schools may be affected by increased class size as a consequence of free primary education.

\subsection{Conceptual Framework}

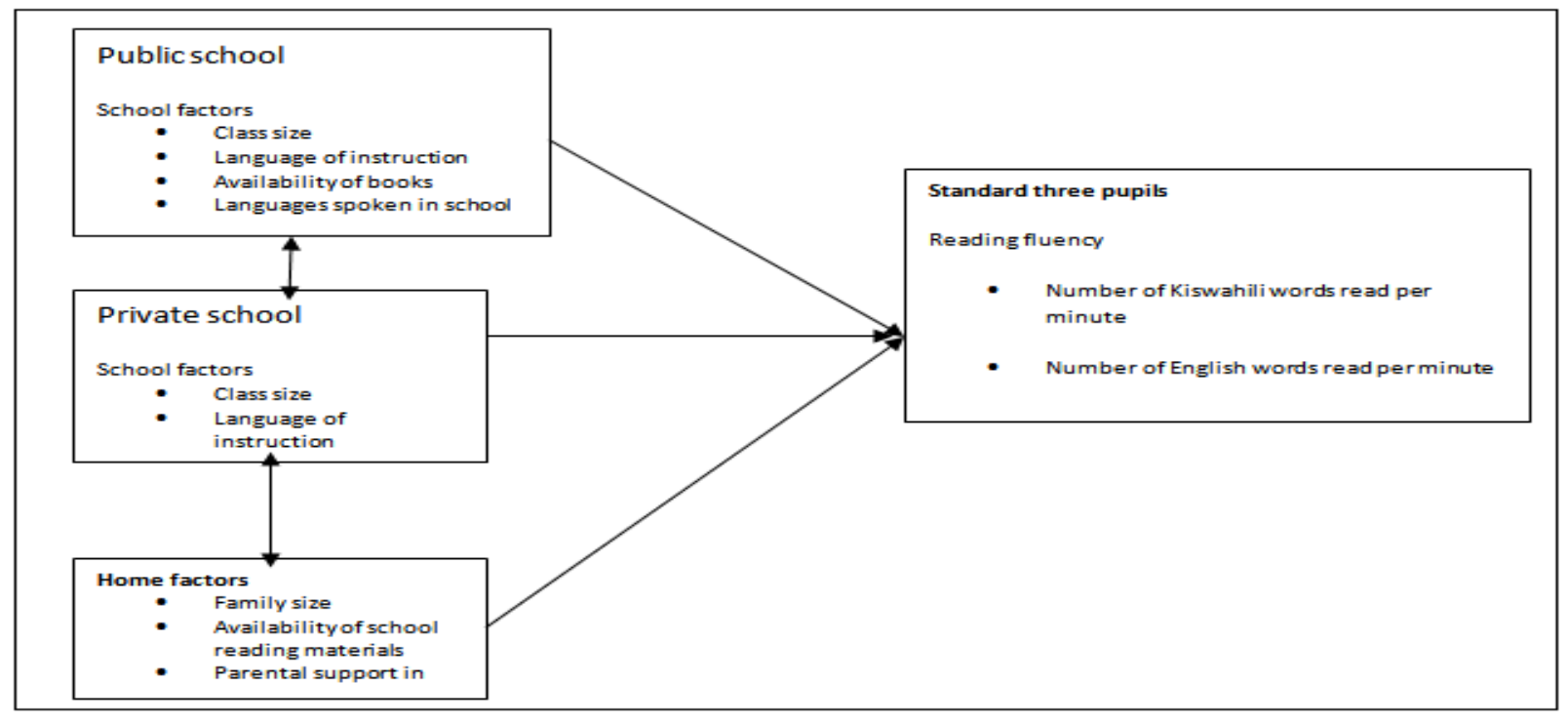

Figure 1. Interaction between school and home factors with reading fluency 


\subsection{Statement of the Problem}

Development of reading fluency is an important precursor of intellectual growth during the school years and beyond. Children who develop reading fluency early develop understanding of school subjects thus promising good academic grades. One determinant of reading fluency during the early school years is the absence of learning disability which is genetically determined. The second determinant is the home environment which may be enriched or impoverished with regard to early reading support. Some homes provide supportive environments for the development of early reading fluency by providing children reading books and they also provide the children support through such behaviors as creating time to read for the children or overseeing that school work is done. The third determinant is the school and the kind of environments they provide to support early reading fluency. Some schools are enriched and support children by providing books and reading experiences. The schools have a responsibility of actualizing the language policy of using the language of the catchment area in teaching during the early school years. Both the home and the school provide the psycholinguistic environment that nurtures early reading fluency. Children are likely to become fluent readers by standard three if they are instructed in the language of the school catchment area or mother tongue. The problem addressed by the current study is the fact that in the location the study was carried out children were exposed to many languages both in school and at home for example, children may be exposed to English, Kiswahili and a mother tongue concurrently may interfere with children's reading fluency in standard three. In addition, when the languages the teacher, the parents and the friends use are all different this interferes with reading fluency at standard three. Another issue of concern in the current study is the unequal opportunities children are exposed to both at home and in the school to the extent that some children have the advantage of having adequate reading materials and supportive parents while others are disadvantaged and have few or no reading materials outside school.

The purpose of the study was therefore to establish the levels of reading fluency in two languages that the children are exposed to early in their school life. These are Kiswahili and English. The study also sought to establish the home and school factors that that support early reading fluency such as provision of literary materials, language of instruction among the children studied.

\subsection{Study Objectives}

The major objective of the study was to establish levels of reading fluency in Kiswahili and English languages among standard three pupils among the schools studies and establish the home and school factors that support development of reading fluency among the children under investigation.

\section{Research Methodology}

The study adopted a survey research design. Four primary schools were purposively selected for the study of which two were private primary schools while the other two were public primary schools. The standard three pupils in the public schools were 108 pupils and they were all involved in the study. The standard three pupils in both private schools were 54 yielding a total sample of 162 pupils. Three research instruments were used to collect the study data. The first instrument was a one-minute reading test in Kiswahili while the second instrument was oneminute reading test in English both composed by the researcher. These were used to collect the reading fluency data in Kiswahili and in English. The third instrument was a paper-based questionnaire that was used to collect the demographic variables as well as the school and home factors that nurture reading fluency. The researcher wrote letters explaining the purpose of the study and requesting for permission to conduct the study to each school management of the schools involved. Each school gave a day when the pupils had finished their first term examinations so as not to interfere with the schools programs. The one minute reading fluency test was administered in the order of first the English passage and then the Kiswahili passage to each pupil at a time. This was done in line with Rasinski who averred that reading fluency can be assessed within sixty second [14]. The pupils also responded to the questionnaire items meant to establish the home and school factors that nurture reading fluency. Descriptive and inferential statistics were used to analyze the data.

\section{Findings of the Study}

\subsection{Study Subjects}

The study subjects consisted of all the standard pupils in the four primary schools investigated and the results are presented in Figure 2.

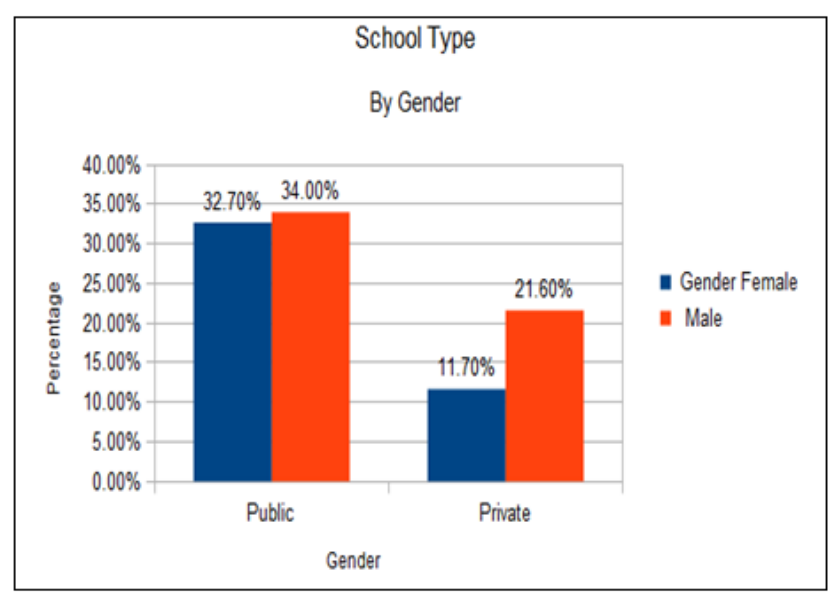

Figure 2. Type of school

The study subjects consisted of 108 children were drawn from public schools of these 53 were females while 55 were males. The pupils from private schools were 54 of which 19 were girls and 35 were males. The school type is important in determining reading fluency in the sense that if the school is public or private it determines the kind of reading fluency support children are accorded. The public schools are most likely to have overcrowded classrooms with few reading resources while the private schools tend to have fewer pupils per class and more books per pupil. 
In addition children from lower social economic status attend public schools while those from middle class attend private schools a situation that further advantages or disadvantages pupils.

\subsection{Home Background Factors}

The study was interested in establishing home background factors such as the people the children lived with. Of interest was whether children lived with both parents or not. This is likely to have a bearing in reading fluency in that children living with both parents are more likely than their counterparts having different living arrangements to have both material and psychological support beneficial for early development of early reading fluency. The findings were presented in Figure 3.

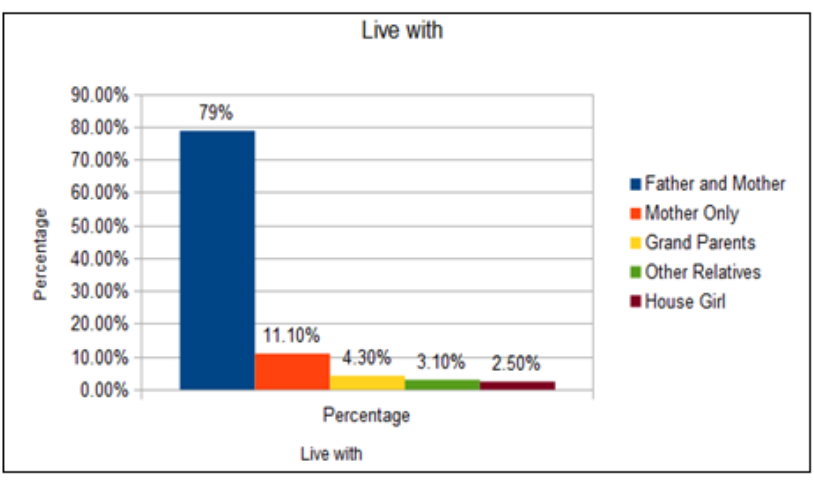

Figure 3. People children live with

Majority of the pupils reported that they lived with both parents (79\%) while 11\% lived with mother only, $4.30 \%$ with grandparents and few living with other relatives and house girls (3.10\% and2.50\%)respectively. The results did not reveal any difference in reading fluency in Kiswahili based on whether children live with both parents, grandparents or other people $\left(\chi^{2}=12.29, \mathrm{df}=8, \mathrm{p}>0.05\right)$. there are studies that seem to concur that when parents are living with their children they are most likely to be involved in the children's academic life which has the benefits of promoting both motivation and achievement in their children [6,7].

Another home background factor of interest to the study was to establish the number of siblings the children under investigation lived with at home. This was deemed important because reading fluency is likely to be influenced by the family resources availed to each child which is in turn is determined by how many children the family is raising at any one time. The assumption is that families with fewer children would be more likely to provide reading materials than families with more children. Findings were presented in Figure 4.

Majority of pupils reported having between one and two siblings $35.20 \%$ and $24.10 \%$ respectively while $18.50 \%$ reported having three siblings. Few children reported having 4 (7.40\%), 5 (6.80\%), 6 (1.20\%) and 8 (1.90\%) siblings while $4.90 \%$ did not respond to the item. The results did not show significant difference in reading fluency among pupils from home backgrounds where the pupil has varying number of brothers and sisters $\left(\chi^{2}=\right.$ 11.47, $\mathrm{P}>0.05)$.

In addition the study wished to establish the number of siblings attending school. This was deemed important because siblings attending school could support the child with reading and at the same time sibling attending school determine the amount of reading materials a family may have to support each child and thus a family with fewer children may have more materials while the families with more children may have fewer materials for all the children. Results are presented in Figure 5.

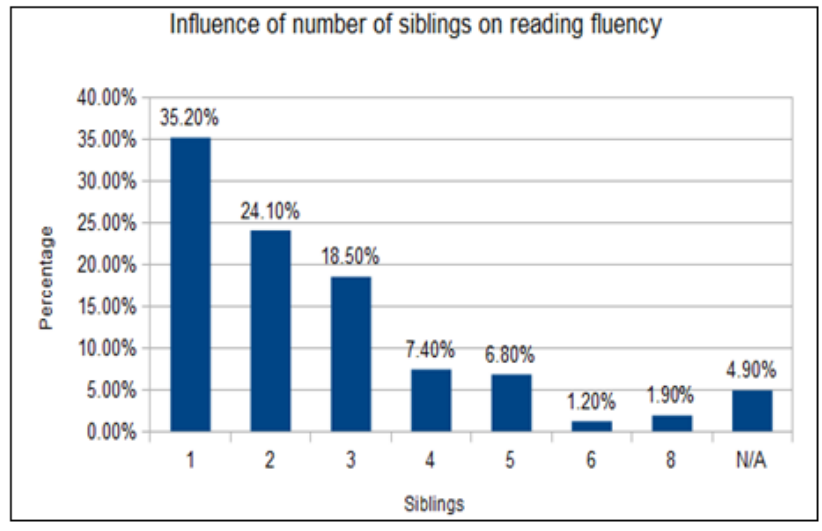

Figure 4. Number of siblings

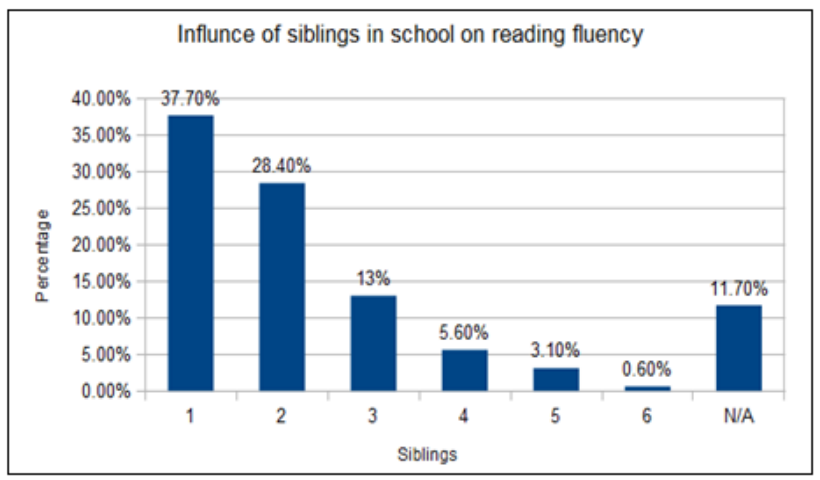

Figure 5. Number of siblings attending school

The findings revealed that many of the children under investigation had siblings attending school with $37.70 \%$ and $28.40 \%$ having 1 and 2 respectively while $13 \%$ and $5.60 \%$ had 3 and 4 siblings attending school respectively. Fewer children reported having 5 (3.10\%) and 6 (0.60\%) siblings attending school with 11.70 returning a no response to the item. There was significant difference in reading fluency among pupils from home backgrounds with brothers and sisters in school with children with fewer siblings in school demonstrating better fluency $\left(\chi^{2}=\right.$ 11.40, $\mathrm{P}>0.05)$.

\subsection{Language Spoken at Home}

The language spoken at home was factor investigated by the study. This was deemed to be important because ideally initial reading fluency should be based on the language children speak in their homes. Findings are presented in Figure 6.

The study findings established that majority of pupils (39\%) spoke Kikuyu at home while a large Percentage (34.60\%) were not willing to reveal the languages spoken at home. The findings also revealed that many language groups were represented as shown by the following percentages Dholuo (6.8\%), Kamba (6.20\%), Kisii, (4.30\%) and Luhya (3.10\%) respectively. The children who reported speaking other languages at home were; Sudanese (1.25\%), Samburu (1.20\%) and Somali (1.20\%) 
respectively. In addition very small percentages reported speaking other languages such as; Embu (0.60\%), Meru (0.60\%) and Oromo (0.60\%).

The findings confirmed findings from other researchers that Kenya is ethnically heterogeneous and as such people from different ethnic languages are found living in the same locality a situation that complicates the environment of early reading in the sense that the children are not introduced to reading in a language that they are familiar with [15]. The findings further revealed that that the children hardly spoke Kiswahili or English while at home which means that what is learned in school is not supported by home linguistic practices ${ }^{[15]}$. It thus means children are taught in Kiswahili and English before they master the sounds and match them with the symbols a cognitive activity that takes time ${ }^{[15]}$. Since the education system does not allow for such time the children find themselves submerged. The results present a second challenge of exposing children to many languages early in life which may interfere with the acquisition of both semantics and syntax of second languages which in the Kenyan case are Kiswahili and English. The concern in this case is that children who have not mastered oral language well enough during early school experiences ran the risk of being unable to catch up with academic achievement [3].

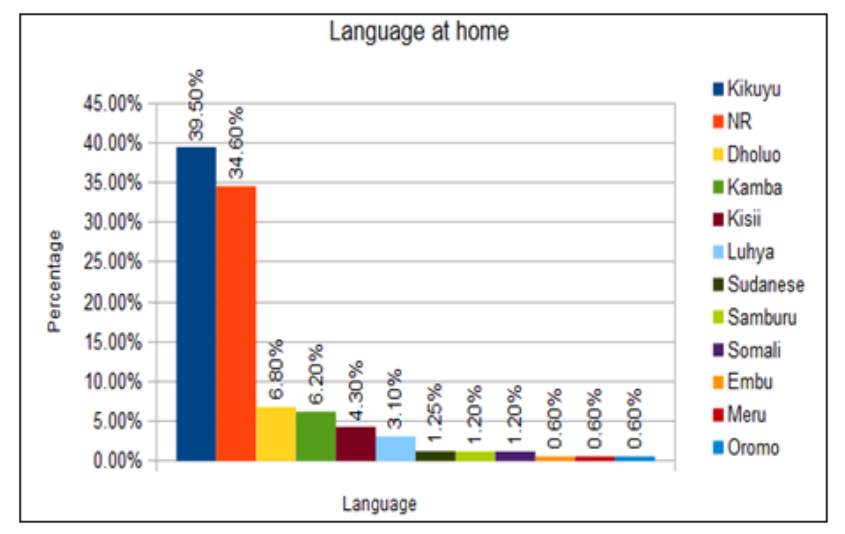

Figure 6. Languages spoken at home

The study investigated other languages spoken at home because. This was deemed important in this study because Kenya is a multilingual country and children are exposed to several languages from home and then at the school. The findings are reported in Figure 7.

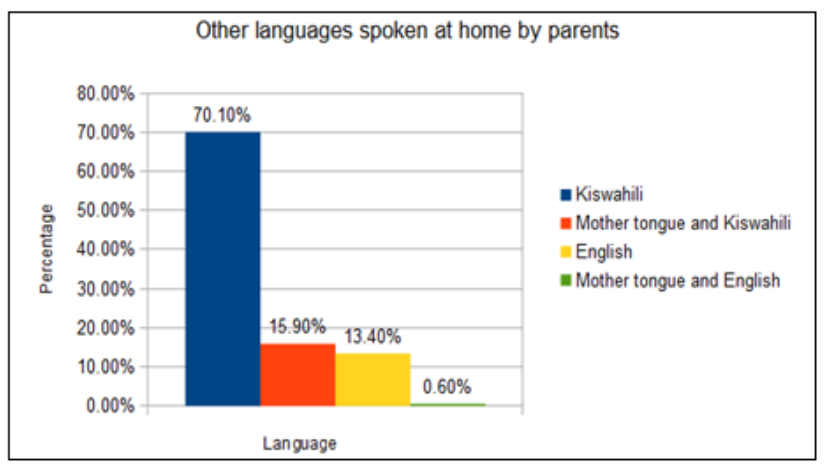

Figure 7. Other languages spoken by parents at home

With regard to this question the study findings showed that majority of parents speak Kiswahili (70.10\%) while
(15.90\%) speak mother tongue and Kiswahili. Those who reported that their parents spoke English were (13.40\%) while negligible percentage (0.60) spoke mother tongue and English. These results further reveal the complicated language situation which many children are multilingual speaking an ethnic language and Kiswahili and also being exposed to English. This pattern of linguistic exposure is found in many places in the world and according to researchers it is beneficial since knowledge of one language is known to enhance the learning of other languages [16,17]. Even with these advantages of multilingualism there is the concern about the learning conditions where the children do not have sufficient books and other materials to support development of early reading fluency. The $70 \%$ who with parents who spoke Kiswahili may have the advantage that this complements the language of instruction in lower primary schools in Kenya but the other 30\% may have challenges of trying to master several languages concurrently at a time that is critical for development of reading fluency. In line with this research has associated exposure to many languages early in life with negative effects on children's reading fluency since it is likely to interfere with how children learn to think as well as how the development cognitively [18].

\subsection{Overseeing of Homework}

The issue of who oversees a child's homework is important as it reveals the academic activities of a family. Children who get parental support for academic work are more likely than their peers to have a head-start in reading fluency. The findings are presented in Figure 8.

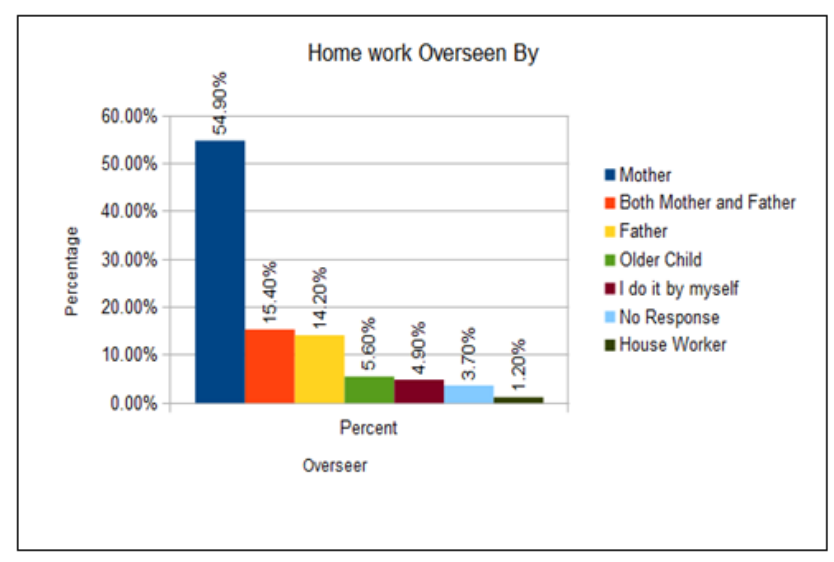

Figure 8. Overseeing homework

The findings revealed that for majority of children it was the mother who oversaw their homework (54.90\%). Those who reported that both mother and father were involved in overseeing homework were $15.40 \%$ who reported that the father alone was involved were $14.20 \%$ those who reported that other people and not the parents oversaw the homework were older child (5.60\%), Self (4.90\%), no response (3.70\% and house worker $(1.20 \%)$. Chi-squire test for the difference in English and Kiswahili fluency for children from home backgrounds where completion of homework is overseen by different people was insignificant. The chi-squire test statistics were $\left(\chi^{2}=15.54, \mathrm{df}=24, \mathrm{p}>0.05\right)$ and $\left(\chi^{2}=11.16, \mathrm{df}=12, \mathrm{p}>0.05\right)$ for English and Kiswahili fluency respectively. 


\subsection{Last Time Parent Read a Story Book for the Child}

It was of interest to the study to establish the last time when the parent read a story for the child. This was because the academic activities of the family have a bearing on development of reading fluency with children with involved parents becoming more fluent than those without involved parents. The results are presented in Figure 9.

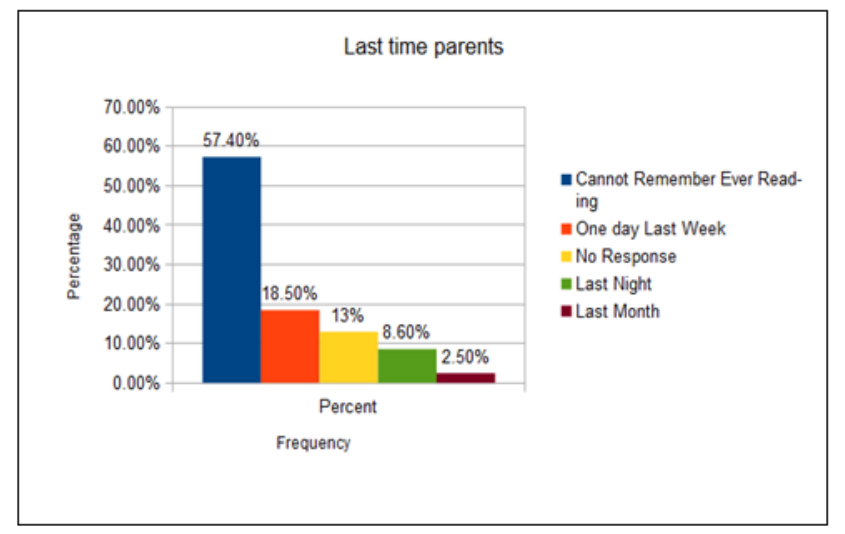

Figure 9. Last time a parent read a story to the child

The results revealed that majority of children (57.40\%) could not remember the last time a parent read a story for them. The children who remembered the parents reading for them a story in the last week, last night and last month were $18 \%, 8.60 \%$ and $2.25 \%$ respectively while those who turned in a no response were $13 \%$. The Chi-squire test for the difference in English and Kiswahili reading fluency for children from home backgrounds where parents read the story on the previous day, previous week or last month were not insignificant. The chi-squire test statistics were $\left(\chi^{2}=11.52, \mathrm{df}=16, \mathrm{p}>0.05\right)$ and $\left(\chi^{2}=5.79, \mathrm{df}=8, \mathrm{p}>0.05\right.$ for English and Kiswahili fluency respectively.

These results are significant as they reveal that the parents of the children studied have not established the culture of reading stories for their children and as such they leave the work development of reading fluency to the school and teachers alone. This is in line with studies that have established that when parents help in homework they may also provide some tutoring to their children which may help to improve children's reading fluency [13]. The challenge in this rests in the fact that parents and teachers may not read for children because they may not understand the benefits of doing so [19]. Children who do not have the benefit of parents and teachers reading for them lose in the sense that they do not hear how words are articulated and they may not benefit from improved vocabulary.

\subsection{Numbers of Books Children have in Public Schools}

The study wished to establish the numbers of English books children in public schools had. This was important to the study because reading fluency is related to the exposure to print that the child receives at an early age. The results are presented in Figure 100.

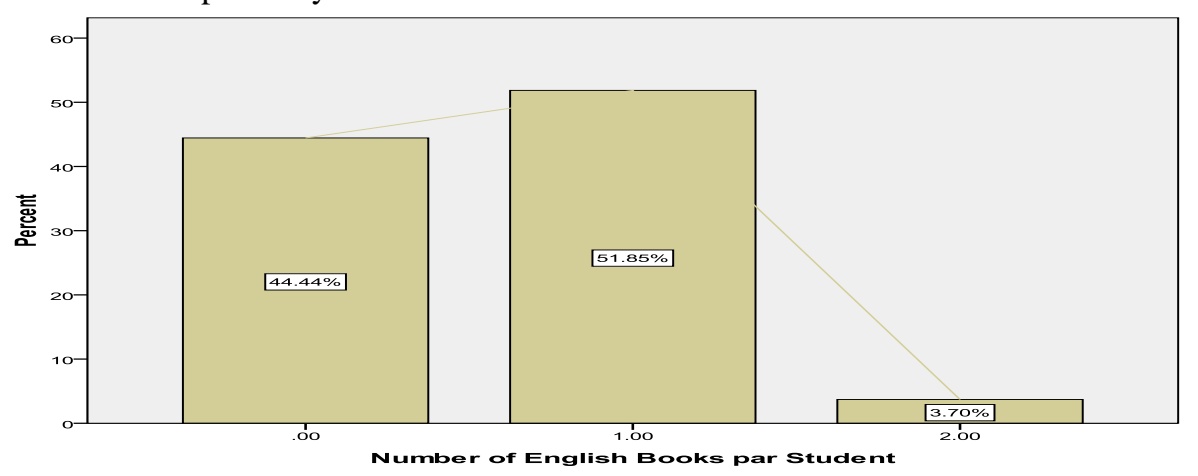

Figure 10. Number of English books children had

The results revealed that $44.44 \%$ did not have an English book while $51.85 \%$ had only one book while $3.70 \%$ reported having 2 books. According to research an important determinant of reading has been identified as exposure to print children as it helps aids acquisition of grammar, vocabulary, pragmatics and discourse [3]. By inference these results indicate that the majority of children studied were found to be at a disadvantage as they did not have adequate exposure to reading materials which may jeopardize their reading fluency which has a bearing on the quality of words and quality of language [3].

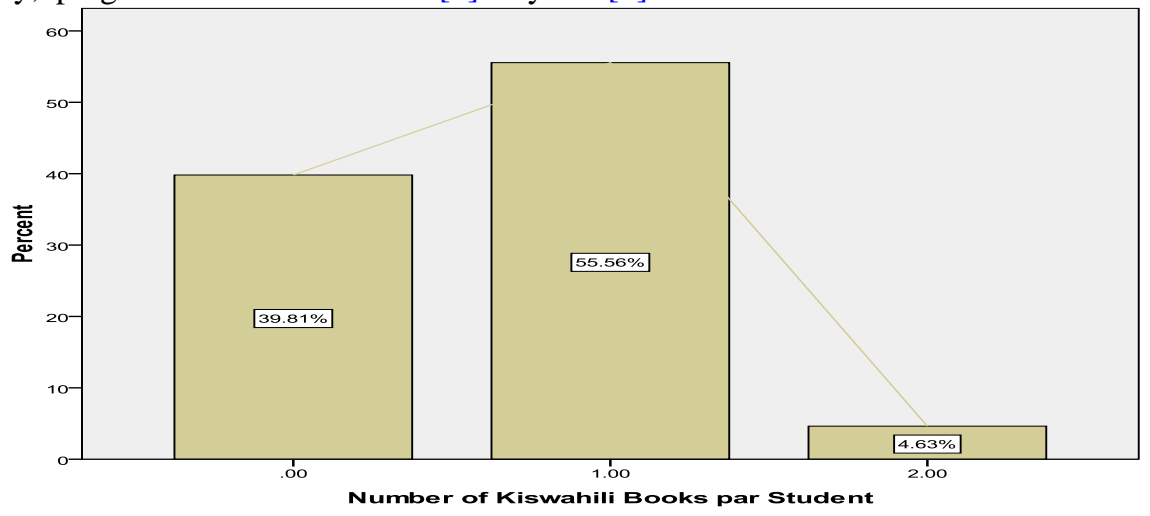

Figure 11. Number of Kiswahili books children in public schools had 
The number of Kiswahili books available to the child had was investigated was intended to establish the number of Kiswahili books standard three children in public primary schools had. The findings are presented in Figure 111.

The findings revealed that $39.81 \%$ of the children reported having no Kiswahili books while 55.56\% reported having only one Kiswahili book and 4.63\% reported having 2 Kiswahili books. These results confirm further the disadvantaged position the pupils in public primary schools an issue which militates against development of early reading fluency. The results seem to confirm like other studies that associate lack of instructional materials with retarded language learning [20].

\subsection{Number of English Books per Pupil}

Investigation of the number of English books pupils had was important because possession of books would increase the chance of reading them thus ensuring early reading fluency. Findings were reported in Figure 122.

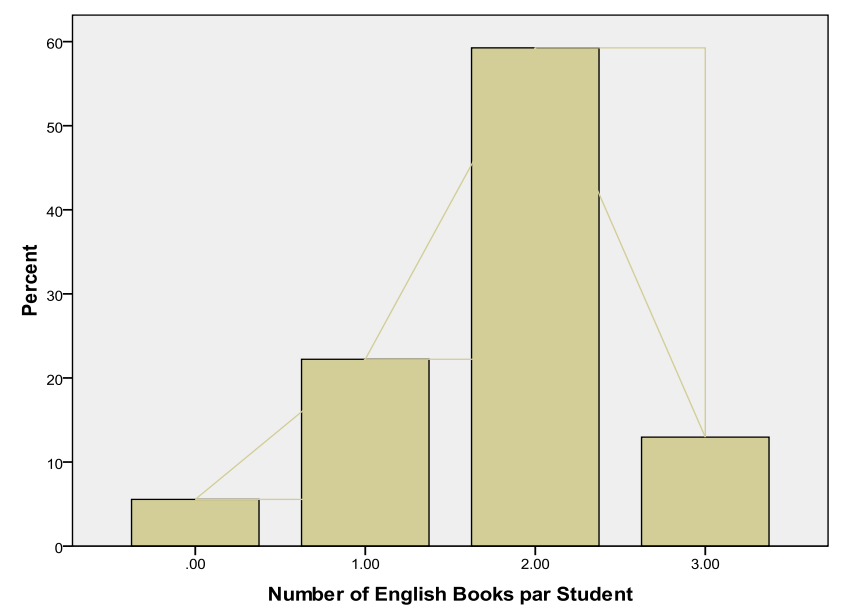

Figure 12. Number of English text books

The results showed that all children from private schools had English text books. About 24\% had one book each while about $48 \%$ had two English books each and $12 \%$ had three books each. These findings show that children in private schools have advantage in reading fluency over their counterparts in public primary schools and hence may be more fluent in reading than.

\subsection{Kiswahili Books per Pupil}

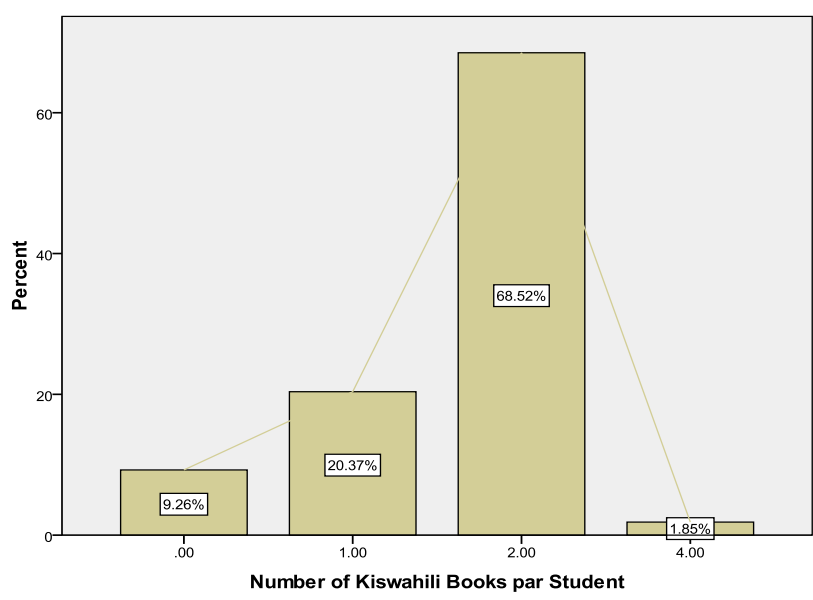

Figure 13. number of Kiswahili per child in private schools

Investigating the number of Kiswahili books the children had was important. The results are presented in Figure 133.

The results show that only $9.26 \%$ of children in private schools reported not having any Kiswahili books while $20.37 \%$ reported having one book and $68.52 \%$ reported having two books and 1.85\% reported having 4 books. According to results all the children have Kiswahili books a situation which may give the children advantage in early development in reading fluency unlike their counterparts in public schools who reported fewer books.

\subsection{Language Spoken by Standard Three Pupils}

The item intended to establish the language the children under study spoke with their friends. The findings are reported in Figure 144.

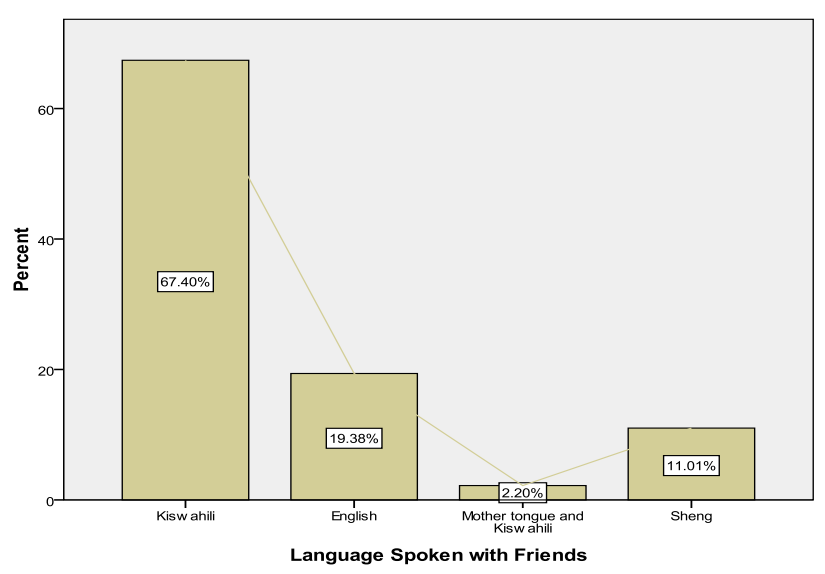

Figure 14. language spoken with friends

The study findings established that $67.40 \%$ of the children reported using Kiswahili while $19 \%$ spoke English and 2.20 spoke mother tongue and Kiswahili while $11.01 \%$ spoke Sheng, a slang characterized by code mixing with expressions borrowed from Kiswahili and English and used by young people as part of popular culture. These findings are encouraging in the sense that the children who speak Kiswahili are likely to have advantage in reading fluency unlike their counterparts who speak mixed languages or Sheng.

\subsection{Language Used by Teachers in School}

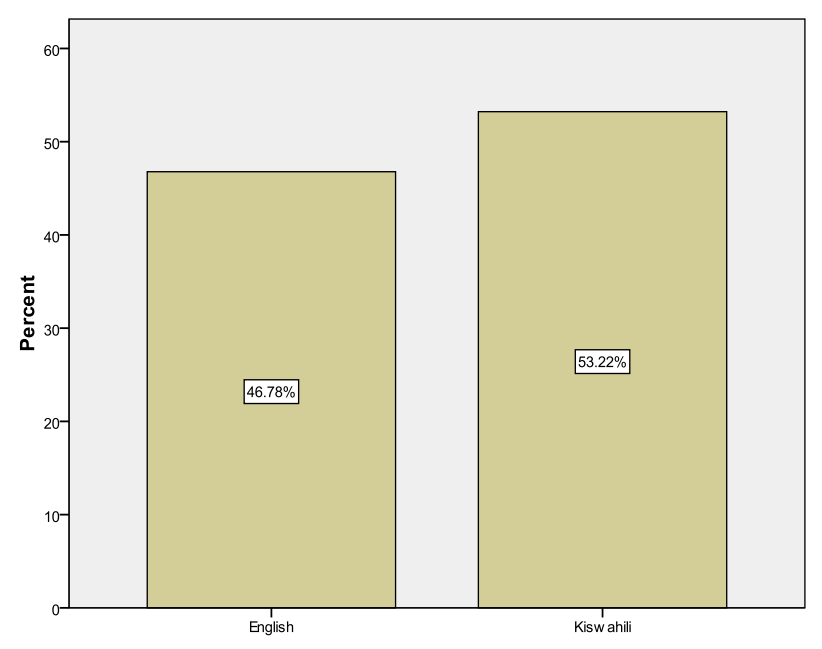


Figure 15. Language used by teachers in school

This item intended to establish the language used by teachers while in school. This is important because when children hear the spoken language and they write it, acquisition of reading fluency is enhanced. Findings are reported in Figure 155.

According to the findings $46.78 \%$ speak English while $53.22 \%$ speak Kiswahili. The findings confirmed that the children under investigation were exposed to both languages almost equally which was in concurrence with research that express the view that in developing countries foreign languages pervade the education system a situation bound to put the children to a disadvantage in the sense that it deprives them the opportunity to learn in the language they are already familiar with and promotes rote learning which in some cases may lead to intellectual disengagement [15].

\subsection{Reading Fluency among Standard Thee Children}

The objective wished to establish the levels of reading fluency in the two languages mostly used in schools

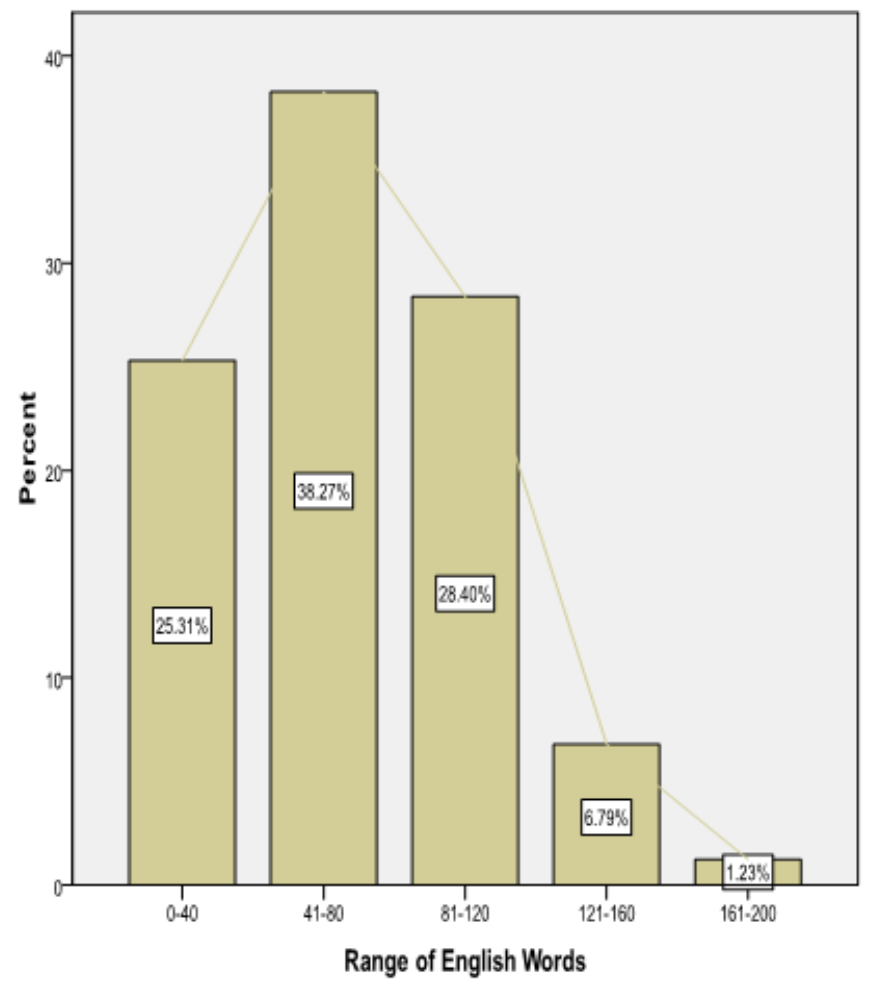

Kiswahili and English among the children under investigation. To achieve this, each child was given an English story to read and the number of words read in one minute recorded. The child was also given a Kiswahili story to read and the number of words read in minute also recorded. The objective intended to establish the reading fluency in English and Kiswahili among the children studied. The findings were presented in Figure 166.

The findings revealed children who read 0-40 English words were $25.3 \%$ while those who read $41-80$ words were $38.3 \%$. In addition children who read $81-120$ word were $28.4 \%$ with those reading $121-160 \%$ were $6.8 \%$ and $161-200$ being $1.2 \%$. The range of Kiswahili words read were $0-40$ by $33 \%$ and $41-80$ by $51.2 \%$ while $81-120$ were read by $15.4 \%$ of the children. These findings show that children are more fluent in English than Kiswahili although Kiswahili should be the language of instruction in lower primary school according to the education policy. The findings confirm findings that in many regions in Kenya English and Kiswahili are used. The findings further concurred that that in developing countries foreign languages pervade the education system and as such interfere with early development of reading fluency [15].

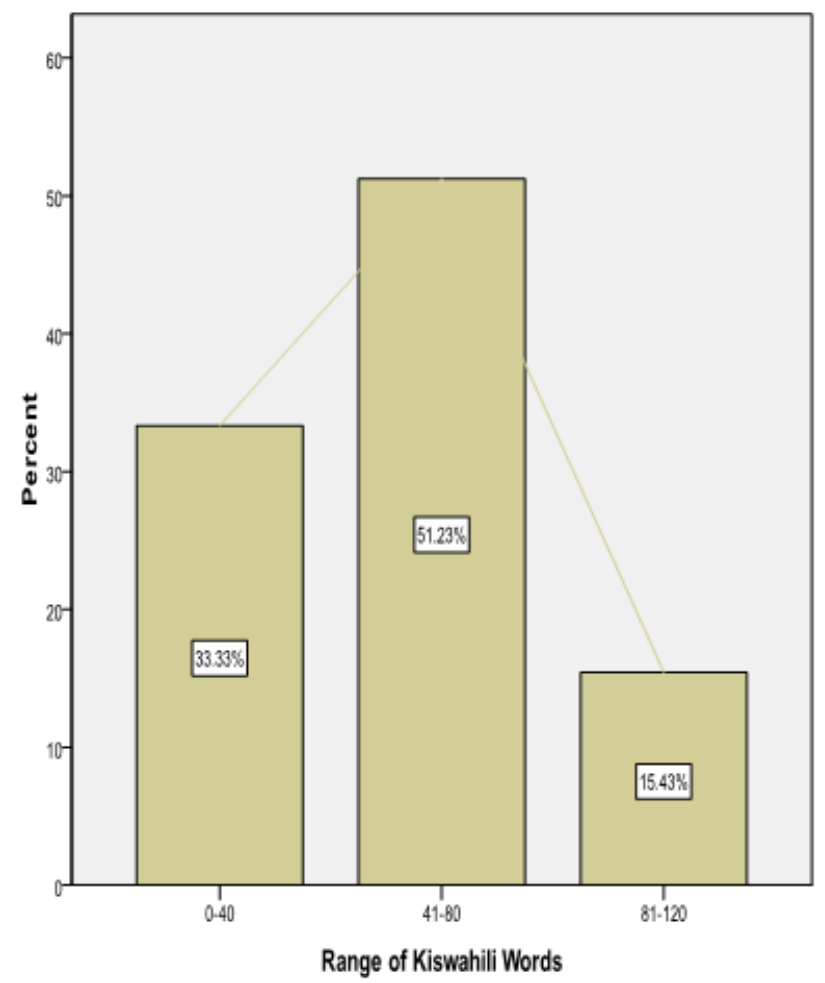

Figure 16. reading fluency in English and Kiswahili

\subsection{Reading Fluency in English among Children in Public and Private Schools}

The objective intended to establish the levels of reading fluency among children in public schools and those in private schools. The findings were presented in Figure 177.

The findings revealed that children in public primary schools were less fluent in the reading of English as $36.11 \%$ read $0-40$ words and $39.81 \%$ reading $41-80$ words. 81-120 were 18.52 while those who read 121-160 were $18.52 \%$ and those reading $161-200$ words were $0.93 \%$. Their counterparts in private schools displayed more fluency with $3.70 \%$ reading $0-40$ word and $35.19 \%$ reading 41-80 words. Children who read 81-120 words were $48.15 \%$ and those reading121-160 words were $11.11 \%$ and $1.85 \%$ reading between $161-200$ words. These results reveal that children in private schools were more fluent in reading English a situation that can be explained by differences in learning environments as well as availability of reading materials. The findings build a case for increasing reading materials in the public schools and also the creation of learning strategies that include creating enabling environments where children can engage in repeated readings in various forms as was advocated studies [21]. Favourable environments have also been 
found to support bulding up of vocabulary among young

Type of School: Public

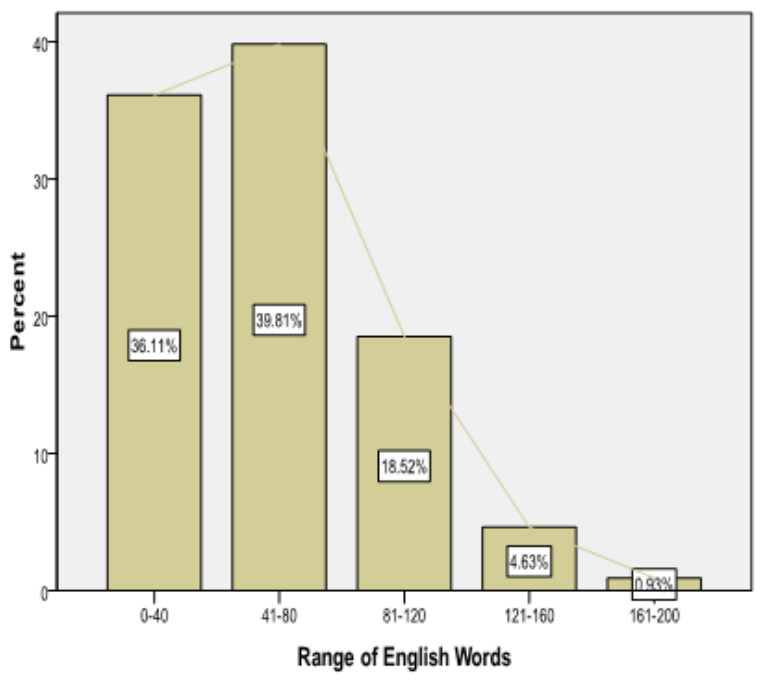

children [22].

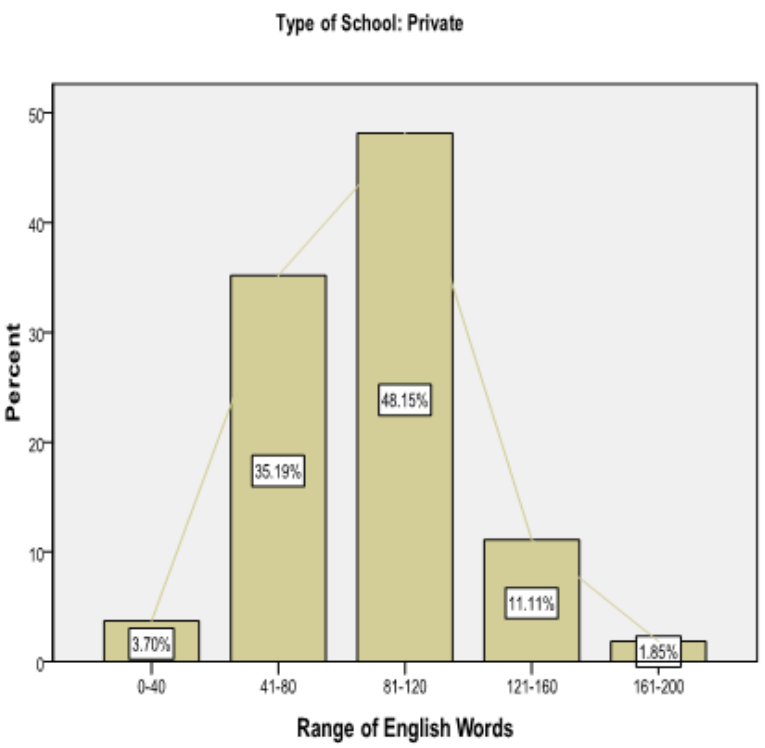

Figure 17. English reading fluency among children in public and private schools
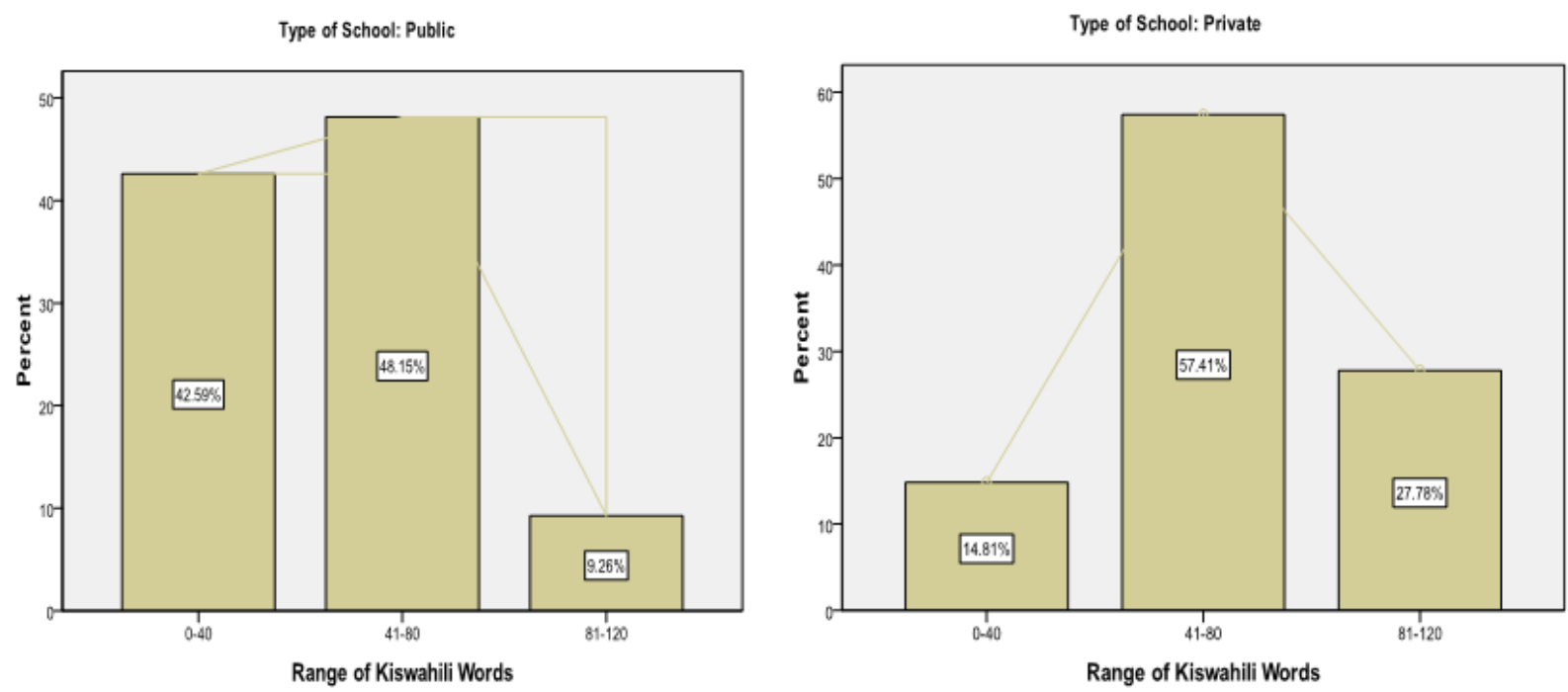

Figure 18. Kiswahili reading fluency among children in public and private schools

The findings revealedfurther differences in reading fluency between children in public and private schools. Among the children in public schools $42.59 \%$ read $0-40$ words and $48.15 \%$ read $41-80$ words while those who read 81-120 words were 9.26\%. Among their counterparts in private schools $14.81 \%$ read $0-40$ words while $57.41 \%$ read 41.80 word and $27.78 \%$ read $81-120$ words.

\subsection{Statistical Analysis}

The results of English reading fluency test revealed that the maximum number of word read were 171 and the minimum 0 with the range of 171 words and the mode of 69 words per minute. Computation of Man-Whitney Test showed that a significant difference in reading fluency between pupils in public and private schools and the difference is in favor of pupils in private schools. The results of Kiswahili reading fluency test showed that the maximum number of words read were 118 and the minimum was 0 with a mode of 61 words. In public schools the mean rank in English fluency was 68.59 while that of private schools was 107. In public schools
Kiswahili reading fluency was 71.60 and in private schools 101. Computation of Mann-Whitney revealed a significant difference in reading fluency between pupils in public and private schools with pupils in private schools being more fluent in reading $(\mathrm{u}=1522.00, \mathrm{p}<0.05)$.

In the English fluency test girls mean rank was 89.56 words per minute while boy's mean rank was 75.06 while the Kiswahili mean rank for girls was 88.15 and boys reading an average of 76.18 words per minute. The computation of Mann-Whitney Test revealed a gender difference in reading fluency in favor of girls $(u=2660$, $\mathrm{p}<0.05)$.

\section{Conclusion}

In conclusion, the findings of the study revealed that although the pupils are exposed to many ethnic languages they mainly speak English and Kiswahili at home, with peers and in school. The findings further reveled that teachers speak the two languages English which is the official language as well as being the language of 
instruction in upper primary school and beyond and Kiswahili which is the national language as well as being the language of instruction in lower primary school. With regard to possession of books, the findings established that many children in public primary schools possessed fewer Kiswahili and English books while their counter parts in public schools. The findings established that there was a significant difference in reading fluency between pupils in public and private schools and the difference with more pupils in private schools being more fluent in both languages than their counterparts in the public primary schools ( $\mathrm{u}=1522.00, \mathrm{p}<0.05)$. the results also revealed as significant gender difference in reading fluency (English) and the difference with girl being more fluent than the boys ( $U=2660, P<0.05$ ). Although the study did not reveal significant difference in reading fluency among pupils from home backgrounds with in relation to number of siblings the pupils had $\left(\chi^{2}=11.47, \mathrm{P}>0.05\right)$ there was a significant difference in reading fluency among pupils from home backgrounds with brothers and sisters in school with pupils with fewer siblings being more fluent $\left(\chi^{2}=11.40, \mathrm{P}>0.05\right)$.

No significant difference in English reading fluency among pupils depending on whom they live with $\left(\chi^{2}=24.20\right.$, df $\left.=16, p>0.05\right)$. The study results showed no significant difference in Kiswahili reading fluency among pupils depending on whom they live with $\left(\chi^{2}=12.29\right.$, $\mathrm{df}=8$, $\mathrm{p}>0.05)$. In addition, the Chi-squire test for the difference in English and Kiswahili fluency for children from home backgrounds where completion of homework is overseen by different people was insignificant. The chi-squire test statistics were $\left(\chi^{2}=15.54\right.$, df $\left.=24, p>0.05\right)$ and $\left(\chi^{2}=11.16\right.$, $\mathrm{df}=12$, $\mathrm{p}>0.05)$ for English and Kiswahili fluency respectively. Whether parents and other people read stories for the children or not was not a significant factor determining reading fluency as revealed by the Chi-squire test for the difference in English and Kiswahili fluency for children from home backgrounds where parents differ in terms of whether they read story books for their children or not was insignificant. The chi-squire test statistics were $\left(\chi^{2}=11.52, \mathrm{df}=16, \mathrm{p}>0.05\right)$ and $\left(\chi^{2}=5.79, \mathrm{df}=8, \mathrm{p}>0.05\right.$ for English and Kiswahili fluency respectively.

\section{Recommendations}

Based on the study findings as well as the conclusions, this study recommends that pupils in public schools be provided with environments that promote development of reading fluency. The parents of such children should be sensitized to take up more responsibility of ensuring that their children have literacy materials and that they take an active role to read story books for their children. The schools too should bargain with the government for better infrastructure, smaller class sizes, and more books. The study also recommends interrogation the language policy in line with what is practical on the ground since the instructional materials in the schools are in English but not Kiswahili. First, the focus should be on the development of materials in the local languages and then enforcing the policies. Since there is a preference of English as a language of instruction, it may become necessary to find out whether it is not fair to recommend it as a language of instruction besides the English books are readily available.

\section{References}

[1] Kuhn, M. \& Stahl, S. (2003). Fluency: A review of developmental and remedial practices. Journal of Educational Psychology. 95. (1), 3-21.

[2] Abadzi, H. (2006). Efficient Learning for the Poor: Insights from the Frontier of Cognitive. Neuroscience. Washington: The World Bank

[3] Fielding, L., Kerr, N., \& Rosier, P. (2007). Annual Growth for all students, Catch-Up Growth for those who are behind. Kennewick, WA: The New Foundation Press, Inc

[4] Jeynes, W.H. (2010). Parental Involvement and Encouraging That Involvement: Implications for School-Based Programs. Teachers College Record, 112(3), 747-774.

[5] Min, X., Kushner, S. B., Mudrey-Camino, R., \& Steiner, R. (2010) The relationship between parental involvement, self-regulated learning, and reading achievement of fifth graders: A path analysis using the ECLS-K database. Social Psychology of Education, 13(2), 237-269.

[6] Fan, W., \& Williams, C. (2010). The effects of parental involvement on students' academic self-efficacy, engagement and intrinsic motivation. Educational Psychology, 30(1), 53-74.

[7] Tan, E. T., \& Goldberg, W. A. (2009). Parental school involvement in relation to children's grades and adaptation to school. Journal of Applied Developmental Psychology, 30(4), 442-453.

[8] Sénéchal, M., LeFevre, J., Thomas, E., \& Daley, K. (1998). Differential effects of home literacy experiences on the development of oral and written language. Reading Re-search Quarterly, 32, 96-116.

[9] Senechal, M. \& LeFevre, J. (2002). Parental involvement in the development of child's reading skill: A five Year Longitudinal Study. Child development, March/April 2002, volume 73, Number 2 , page $445-460$.

[10] Samuels, S. J. (2006). Towards a model of reading fluency. In S. J. Samuels \& A. E. Farstrup (Eds.), What research has to say about fluency instruction (pp.24-46). Newark, DE: International Reading Association.

[11] Kosonen, K. (2005). Education in local languages: Policy and practice in Southeast Asia. First languages first: Community-based literacy programmes for minority language contexts in Asia. Bangkok: UNESCO, Bangkok.

[12] UNESCO. 2010. EFA Global Monitoring Report 2010: Reaching the Marginalized; Regional Overview, Sub-Saharan Africa. Paris: UNESCO.

[13] Bronfenbrenner, U. (1979). The Ecology of Human Development: Experiments by Nature and Design. Cambridge, MA: Harvard University Press.

[14] Rasinski, T. V. (2004). Assessing reading fluency. Honolulu, Hi: Pacific Resources for Education and learning.

[15] Gacheche, K. (2010). Challenges in implementing a mother tongue based language-in-education policy: Policy and Practice in Kenya. POLIS Journal Vol. 4 pp 1-45

[16] Bhatia, T. K., \& Ritchie, W. C. (Eds.). (2006). The Handbook of Bilingualism. Oxford: Blackwell Publishing Ltd.

[17] Modirkhamene, S. (2011). EFL learners' additional language proficiency and academic achievement: Possible effects of bilinguality. Germany: Lambert Publications (LAP).

[18] Wrigglesworth, G. \& Simpson, J. (2008). The language learning environment of pre-school children in indigenous communities. In S. May, ed. Critical Multiculturalism: Rethinking Multicultural and Anti-racialist Education. London: Farmer Press, pp.13-29.

[19] Cunningham, P. (2005). "If they don't read much, how they ever gonna get good?” The reading teacher, 59, (1), 88-90.

[20] August, Diane, and Timothy Shanahan, eds. (2006). Developing Literacy in Second-Language Learners: Report of the National Literacy Panel on Language, Minority Children, and Youth. Mahwah, NJ: Erlbaum.

[21] Chomsky, C. (1978). When you still can't read in the third grade: After decoding what? In S. J. Samuels (Ed.), what research has to say about reading instruction (pp. 13-30). Newark, DE: international reading association

[22] Palumbo, T. J., \& Willcutt, J. R. (2006). Perspectives on fluency: English- language learners and students with dyslexia. In S. J. Samuels (Ed.), what research has to say about reading instruction (pp. 159-178). Newark, DE: international reading association. 